\title{
Study on Performance of Bio-based Adhesive for Bonding Tree Leaves
}

\author{
Yifu Yuan ${ }^{1}$, Yan Sun ${ }^{2}$, Muxuan $\mathrm{Li}^{1}$, Yuhan $\operatorname{Sun}^{1}$, Runan Zhang ${ }^{1}$, Fang $\operatorname{Sun}^{1}$, An Mao ${ }^{1, ~ *, ~ Q i ~ L i ~}{ }^{1, ~ *, ~}$ \\ Jiabin Zhang ${ }^{3, *}$ \\ ${ }^{1}$ Key Laboratory of State Forestry Administration for Silviculture of The Lower Yellow River, College of Forestry, Shandong Agricultural \\ University, Taian, China \\ ${ }^{2}$ College of Arts, Shandong Agricultural University, Taian, China \\ ${ }^{3}$ Heilongjiang Institute of Wood Science, Harbin, China
}

\section{Email address:}

dannymaoan@126.com (An Mao), wonderfulliqi2364@126.com (Qi Li), Zhangjiabin_425@163.com (Jiabin Zhang)

${ }^{*}$ Corresponding author

\section{To cite this article:}

Yifu Yuan, Yan Sun, Muxuan Li, Yuhan Sun, Runan Zhang, Fang Sun, An Mao, Qi Li, Jiabin Zhang. Study on Performance of Bio-based Adhesive for Bonding Tree Leaves. American Journal of Agriculture and Forestry. Vol. 7, No. 6, 2019, pp. 297-303. doi: 10.11648/j.ajaf.20190706.19

Received: October 31, 2019; Accepted: November 20, 2019; Published: November 25, 2019

\begin{abstract}
The traditional disposable foam plastic tableware is made from polymer materials. It is not decomposable and could bring serious problem to environment after the tableware is disposed. In order to solve this problem, a new type of green tableware made fromnatural materials (such as tree leaves) is developed and investigated. To obtain a green tableware product with good performance, the keytechnology is the bonding of tree leaves. In this study, the tree leaves were bonded by a type of bio-based adhesive synthesized in our lab. The structure, curing characteristics, and physical/mechanical properties of the adhesive were measured and analyzed. The effects of adhesive application rate, press time, and press temperature on the bonding performance of tree leaves were also investigated. The results showed that the general properties of the bio-based adhesive could meet the requirements for the production of tree leave tableware. After immerged in the water of $63^{\circ} \mathrm{C}$ for 3 hours, some of the bonded leaves could still have good bonds. Considering the production efficiency, cost, decorative effect, and bond performance, the optimal pressing parameters were: adhesive application rate: $100 \mathrm{~g} / \mathrm{m}^{2}$; hot press temperature $70^{\circ} \mathrm{C}$; hot press time $120 \mathrm{~s}$. After bonded by bio-based adhesive, the tree leaves could be used as suitableraw materials for the production of green tableware.
\end{abstract}

Keywords: Tree Leave, Bio-based Adhesive, Green, Bonding, Tableware

\section{Introduction}

With the continuous improvement of people's living standards and the acceleration of life rhythm, more and more people begin to eat fast food. The fast food tableware such as disposable plastic lunch boxes, bowls, plates, etc. are used in huge amount every year. It is estimated that the annual consumption of disposable plastic tableware can be as many as over 10 billion sets and the number is still increasing quickly. The disposable plastic tableware is commonly white or transparent and made from polystyrene (PS), polypropylene (PP), polyvinyl chloride (PVC) and other types of polymer materials [1-3]. These polymers are usually thermoplastics and have advantages of low cost, easy to process, good strength, and light weight. However, due to their polymer nature, the inside chemical bonds are strong and durable which make them very difficult to decompose and be recycled after reaching the end of their service lives [4, 5]. With the development of plastic industry and the improvement of anti-aging technology, these plastics are becoming stronger and lasting longer. The advance of technology could bring more conveniences for production and application, but also could bring problem for recycling and reuse. Because these plastics could not decompose under atmospheric conditions and even are hard to be changed by light, heat, or climate $[6,7]$. Moreover, there are no suitable 
microorganisms or enzymes that could directly decompose them. Therefore, there is still no appropriate way to deal with the disposed plastic tableware. Currently, the disposed plastic tableware could be found everywhere after disposed resulting in serious environmental problems.

Many countries and regions made rules to limit or prohibit the use of disposable plastic tableware that could not decompose naturally, because of its negative impact on the environment. Therefore, a new type of green tableware that is made from natural materials and easy to decompose should be accepted well by commercial market. It will meet the requirements of current environmental rules and have huge market potential.

Currently, there are very few reports on the production and application of degradable tableware made from natural materials [8-10]. In Germany, Pedram and his team invented a new type of tableware that is made of large tree leaves. These leaves were sewed together by lines and press-molded into different kinds of tableware products. After disposed, these products could decompose completely in no more than 28 days under natural condition. However, the large tree leaves are not available everywhere. Most leaves around our living areas are small ones. Therefore, to make sure there will be enough leave resources to make tableware in large quantities in the future, smaller leaves from common tree species are used in our study. Instead of sewing, the leaves are bonded together by adhesive. Before the bonding, tree leaves are first pretreated to remove partial water and to improve waterproof property. Then, the leaves were applied with adhesive and bonded together in a mold to make tableware with different shapes. The adhesive used for bonding tree leaves is developed in our lab. The primary raw materials used for preparing the adhesive are from bio-materials (such as starch, protein, etc.). The adhesive has advantages of good bonding performance, low cost, and environmental-friendly [11]. For the tableware production, the key technology is the bonding of tree leaves. It depends on various parameters, such as adhesive application rate, press time, and press temperature. Therefore, the objective of this study is to investigate the effects of these parameters on bonding performance of the tree leaves.

\section{Materials and Methods}

\subsection{Materials Preparation}

Tree leaves are various on color, toughness, mature time of withering, and decay cycle. It is needed first to make choice oftree species among all kinds of trees. The factors, such as toughness, seasonality, shape, size, and availability should be taken into consideration. Magnolia Grandiflora, France Holly, Chinese Photinia, and Phoenix Tree are on the priorityspecies list (Figure 1). In this study, Magnolia Grandiflora was finally chosen as the raw material to make tableware. They are obtained from nearby forestry station of Tai Mountain. The original moisture content of the leaves is $70-75 \%$.

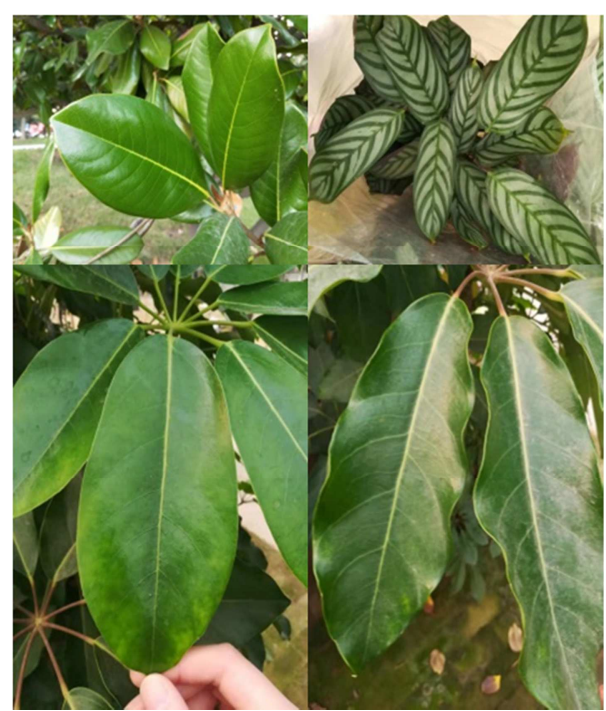

Figure 1. Fresh tree leaves for making tableware.

Cassava starch and corn starch that were used for synthesizing adhesive were provided by local farms. Chemical agents, such as absolute ethanol, glycerol, gelatinization agent, crosslinking agent, and tackifier were obtained from Sinopharm Group Co. Ltd, Beijing.

\subsection{Pretreatment of Tree Leaves}

Natural tree leaves may be polluted by air, insects, dust, and many other materials. These materials might have negative effects on people health after the tree leaves were made into tableware. Therefore, the fresh-picked tree leaves were pretreated before use to remove microorganisms and other dirty materials (Figure 2). The common disinfection methods used for food-related products include: quick cleaning by salt water, washing by fruit and vegetable detergent, washing by starch, and sterilizing by vinegar and baking soda. In this study, the tree leaves were pretreated by absolute ethanol for 30,60, 90, and 120 minutes to remove water and then the surface of the leaves was applied by glycerol uniformly to improve the waterproof performance of leaves. The tree leave specimens were then put in an oven at $80^{\circ} \mathrm{C}$ for 2 hours. After they were removed from oven, they were sealed in the bag.

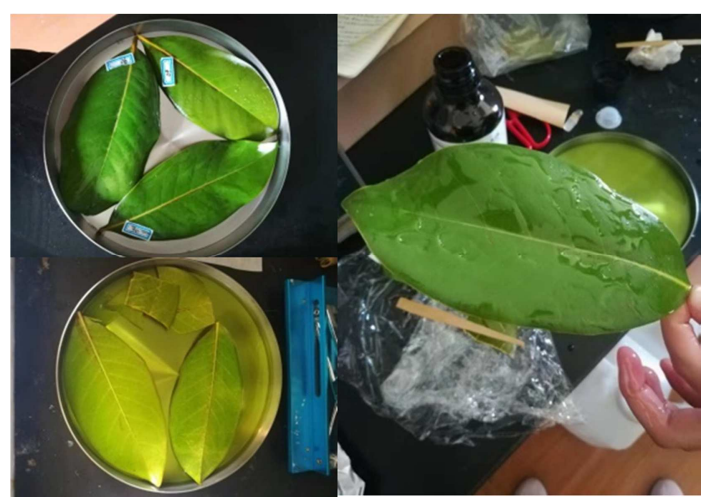

Figure 2. Pretreatment of tree leaves. 


\subsection{Synthesis of Bio-based Adhesive}

The bio-based adhesive was synthesized in the lab. The raw materials used were cassava starch, corn starch, gelatinization agent, crosslinking agent, and tackifier. The reaction apparatus was shown in Figure 3. The synthesis procedure was:

(1) The cassava starch, corn starch, and water were added in a reaction kettle with three necks to form a starch emulsion with a solid content of about $50 \%$.

(2) The reaction mixture (starch emulsion) was stirred quickly and heated to $60^{\circ} \mathrm{C}$, the gelatinization agent and crosslinking agent was added slowly into the reaction mixture, then the reaction was kept at $80^{\circ} \mathrm{C}$ for 1 hour.

(3) Anappropriate amount of tackifier was added to the reaction mixture to adjust the viscosity. The reaction mixture was stirred for about 30 minutes and then was cooled down to room temperature to obtain the adhesive.

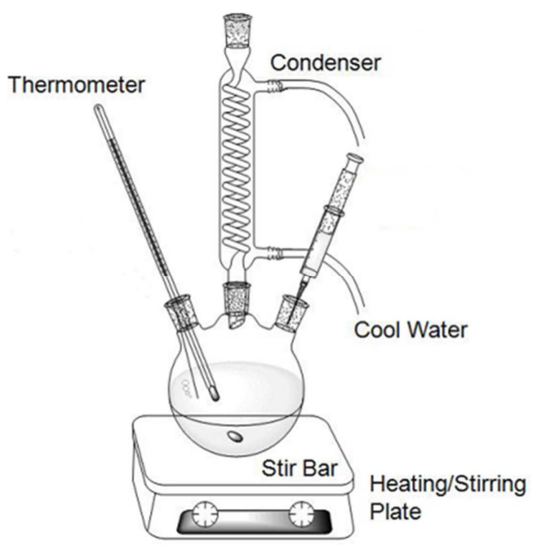

Figure 3. Adhesive synthesis reaction device.

\subsection{FTIR Analysis of Adhesive}

FT-IR analysis was conducted using a Thermo Fisher Nicolet 6700 spectrophotometer (Thermo Fisher Scientific Inc. MA). The liquid sample of the adhesive was dropped on the stage of the spectrophotometer. FT-IR spectra of a total of 64 scans for each sample from 4000 to $600 \mathrm{~cm}^{-1}$ wavenumber were recorded. The functional groups contained in the adhesive were examined through the spectra.

\subsection{Hot Pressing of Tree Leaves}

The hot pressing of tree leaves was performed using a laboratory hot press. The adhesive was applied uniformly onto the surface of leaves. Two leaves were overlaid together and put into the hot press. The adhesive application rates were $100 \mathrm{~g} / \mathrm{m}^{2}$ and $150 \mathrm{~g} / \mathrm{m}^{2}$, respectively. The pressing temperatures were 70 , 80 , and $90^{\circ} \mathrm{C}$, respectively and the pressing times were 60,90 , and $120 \mathrm{~s}$, respectively. The pressing parameters were shown in Table 1. After hot pressing, the bonded tree leaves were taken out from the press and cooled down to room temperature.

Table 1. Hot pressing parameters of tree leaves.

\begin{tabular}{ll}
\hline Adhesive application rate $\left(\mathrm{g} / \mathrm{m}^{2}\right)$ & 100,150 \\
Pressing temperature $\left({ }^{\circ} \mathrm{C}\right)$ & $60,70,80$ \\
Pressing time $(\mathrm{s})$ & $60,90,120$ \\
\hline
\end{tabular}

\subsection{Evaluation of the Properties of the Adhesive}

The viscosity of the adhesive was measured by a Rotational Brookfield Viscometer (Brookfield Engineering Laboratories. Inc., MA). The measurements were performed at $25^{\circ} \mathrm{C}$. Three replicas were performed for each test.

$\mathrm{PH}$ value was determined by an Accumet basic $\mathrm{AB} 15 \mathrm{pH}$ meter (Fisher Scientific Co., PA) at $25^{\circ} \mathrm{C}$. Three replicas were performed for each test.

The curing time of the adhesive was measured at $100^{\circ} \mathrm{C}$ (boiling water).

The solid content of the adhesive was measured by oven-drying the adhesive sample at $125^{\circ} \mathrm{C}$ for 2 hours. Three replicas were performed for each test.

The bonding performance of the adhesive was measured by immersing bonded tree leaves in hot water $\left(63^{\circ} \mathrm{C}\right)$ and calculate the time from the leaves were immerged in the water to the time when the bonds failed (the bond line split). Sixsamples were tested for each measurement.

\section{Results and Discussion}

\subsection{The General Properties of Adhesive}

The general properties of the adhesive were shown in Table 2. The bio-based adhesive was made from bio-materials and without any addition of harmful chemicals. The adhesive is a viscous, semitransparent liquid. The color of the adhesive is light yellow (Figure 4). The viscosity of the adhesive is about $1880 \mathrm{cP}$. This viscosity is suitable for application onto the surface of leaves by brushing or roller coating. There is no addition of acidic or basic products, so the $\mathrm{pH}$ of the adhesive is 7.1, close to neutral. The solid content of the adhesive is $50.5 \%$, which is within the appropriate values of common adhesives. The curing time of the adhesive is $35 \mathrm{~s}$. The fast curing speed can help improve the production efficiency. Generally, the obtained test values were as expected from the synthesis procedures used and were also within the range of industrial values. The small property differences would make little differences in comparing the adhesive bonding values.

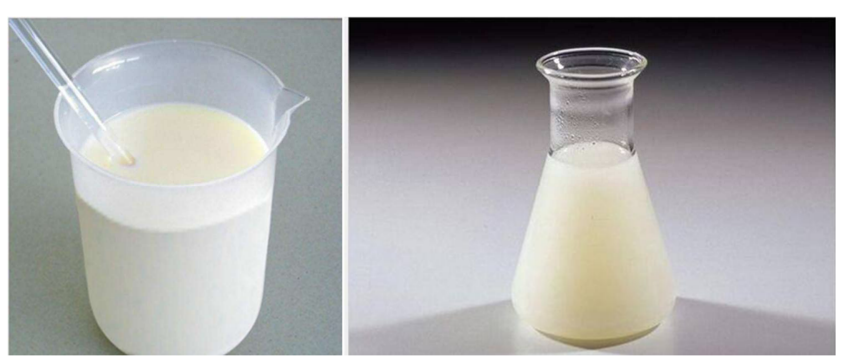

Figure 4. The synthesized adhesive.

Table 2. General properties of the adhesive.

\begin{tabular}{ll}
\hline Appearance & Light yellow, semitransparent liquid \\
\hline Viscosity (cP) & 1880 \\
PH value & 7.1 \\
Solid content (\%) & 50.5 \\
Curing time (s) & 35 \\
\hline
\end{tabular}




\subsection{Chemical Composition of Adhesive}

The chemical composition of the synthesized adhesive was characterized using the FT-IR technique. The spectrum in Figure 5 shows the absorption bands of the liquid adhesive sample. The intense stretching vibration of the $-\mathrm{OH}-$ group at about $3400 \mathrm{~cm}^{-1}$ suggested the adhesive contains a large amount of hydroxyl products and these products should be mainly from starch $[12,13]$. The absorption bands at about $1620 \mathrm{~cm}^{-1}$ and $1470 \mathrm{~cm}^{-1}$ corresponds to the carbonyl group $(\mathrm{C}=\mathrm{O}$ in $-\mathrm{CO}-\mathrm{O}-)$ stretching and $-\mathrm{C}-\mathrm{O}-$ bending vibration, respectively [14]. It indicated that the adhesive synthesized in this study contained - $\mathrm{CO}-\mathrm{O}-$ group in its chemical structure.
This group and - $\mathrm{OH}-$ group provided above would provide some potential chemical reaction opportunities for bio-based adhesives. The absorption bands at about $1660 \mathrm{~cm}^{-1}$ and 3010 $\mathrm{cm}^{-1}$ corresponds to the methylene group $\left(-\mathrm{CH}_{2}-\right)$ and the stretching vibration of $\mathrm{C}-\mathrm{H}$ groups, respectively. These groups were also from starch $[15,16]$. The intense stretching vibration of the aliphatic $-\mathrm{C}-\mathrm{O}-\mathrm{C}-$ group at about $1100 \mathrm{~cm}^{-1}$ suggested the reaction happened between hydroxyl or carboxyl groups [17]. In all, the FT-IR results showed that the bio-based adhesives used for bonding tree leaves in this study have some functional groups that could have potential of chemical reaction with bio-based materials.

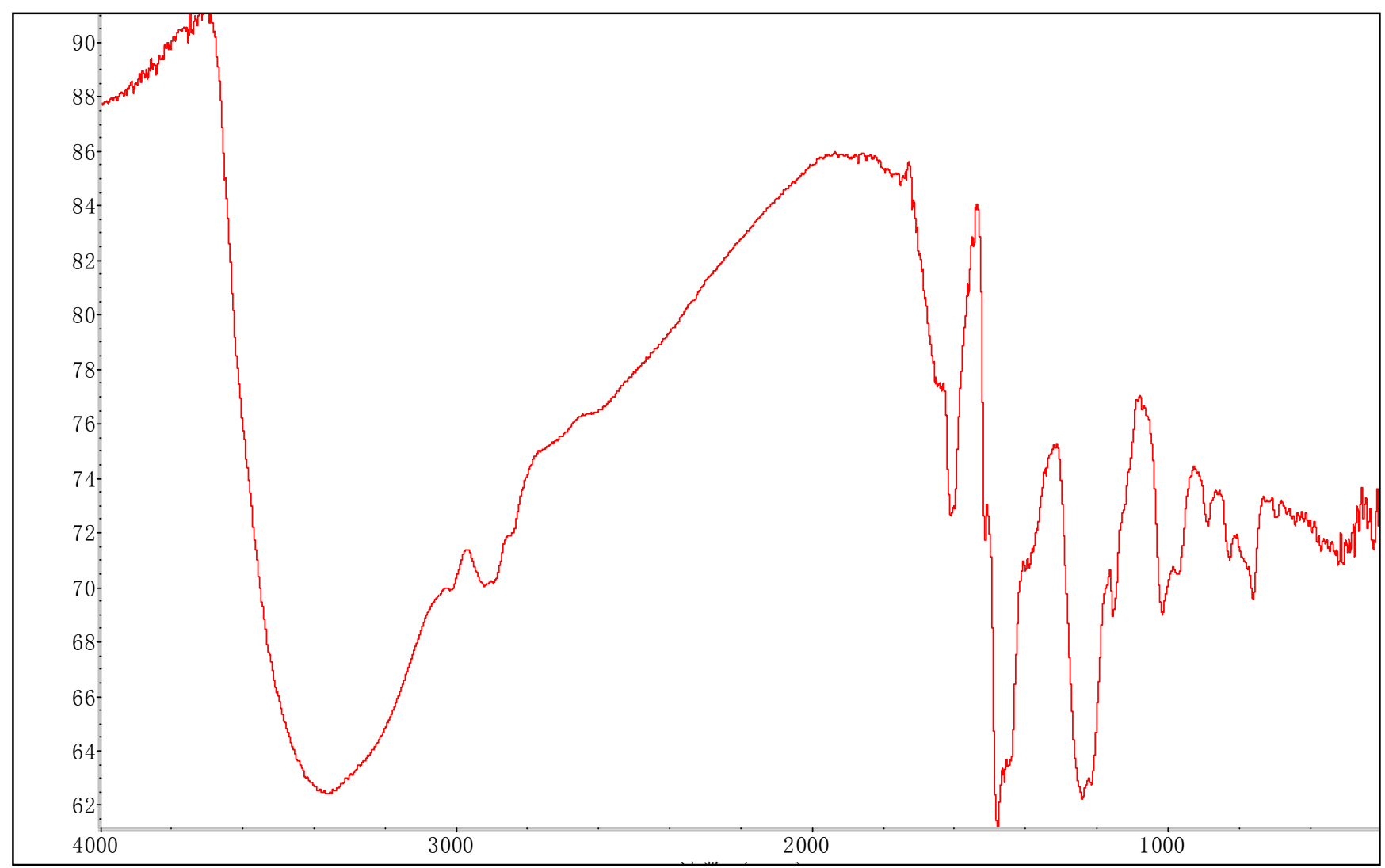

Figure 5. FT-IR spectrum of the bio-based adhesive.

\subsection{Pretreatment of Tree Leaves}

The leaves were freshly picked up from living trees and could contain various kinds of microorganisms, dusts, and water. The original moisture content of leaves was $70-75 \%$. Therefore, the tree leaves were pretreated before use to remove microorganisms and other useless materials. The commonly used disinfection methods include: quick cleaning by salt water, washing by fruit and vegetable detergent, washing by starch, and sterilizing by vinegar and baking soda. In this study, the tree leaves were pretreated by absolute ethanol for 30, 60, 90, and 120 minutes. After treatment, the microorganisms as well as partial water were removed. Then, the surface of the leaves was applied by glycerol. The tree leave specimens were then put in an oven at $70^{\circ} \mathrm{C}$ for 2 hours until the surface became dry. The obtained pretreated tree leaves showed good waterproof performance.

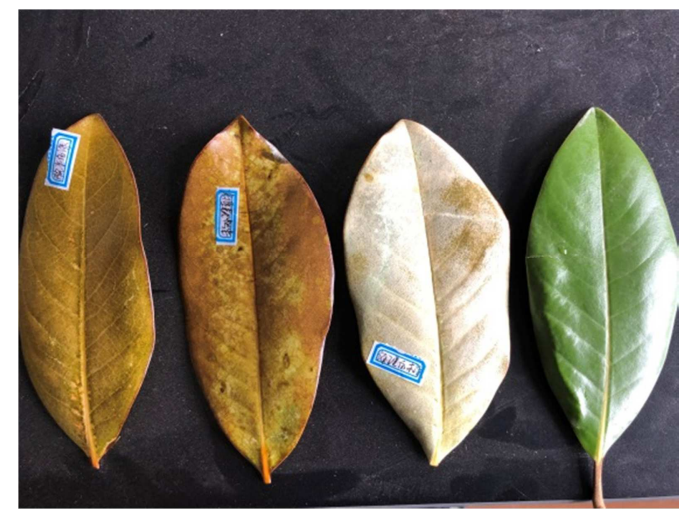

Figure 6. Tree leaves after treatment for different times (from right to left: 30 , 60, 90, 120 minutes). 
Figure 6 shows tree leaves treated by absolute ethanol for different times. After the leaves were treated for 30 minutes, they seemed to be still in green and fresh condition. After the leaves were treated by absolute ethanol for 60 minutes, the color become grey, indicating more water lost. After the leaves were treated by absolute ethanol for 90 and 120 minutes, the color become dark yellow and brown, indicating most water in the leaves lost. Therefore, the treatment of tree leaves by absolute ethanol for 30 minutes was appropriate for making tableware with better appearance.

\subsection{Bonding Performance of Adhesive}

The surface of the tree leaves were applied by the adhesive at rates of $100 \mathrm{~g} / \mathrm{m}^{2}$ and $150 \mathrm{~g} / \mathrm{m}^{2}$, respectively. Then two leaves were pressed together in a hot press. The pressing temperatures were 70,80 , and $90^{\circ} \mathrm{C}$. The pressing times were 60,90 , and $120 \mathrm{~s}$. After hot pressing, the bonded tree leaves were taken out from the press and cooled down to room temperature. The bonding performance of the adhesive was measured by immersing bonded tree leaves in hot water $\left(63^{\circ} \mathrm{C}\right)$ and calculate the time from the leaves were immerged in the water to the time when the bonds failed.

Figure 7 shows the bonded tree leaves after hot pressing. Table 3 shows the bonding performance test results of the adhesive. At application rate of $100 \mathrm{~g} / \mathrm{m}^{2}$, for hot pressing temperature of $60^{\circ} \mathrm{C}$, the bond fail time ranged from 30-60 s, and the color of the bonded leaves were still green. For hot pressing temperature of $70^{\circ} \mathrm{C}$, the bond fail time increased to 100-180 s, and the color of the bonded leaves became light green. For hot pressing temperature of $80^{\circ} \mathrm{C}$, the bond fail time increased to $120-180$ s. However, the color of the bonded leaves became grey. Therefore, at application rate of $100 \mathrm{~g} / \mathrm{m}^{2}$, the optimal hot pressing temperature was $70-80^{\circ} \mathrm{C}$, and the hot pressing time was $90-120 \mathrm{~s}$.

At application rate of $150 \mathrm{~g} / \mathrm{m}^{2}$, for hot pressing temperature of $60^{\circ} \mathrm{C}$, the bond fail time ranged from $50-80 \mathrm{~s}$, and the color of the bonded leaves were still green. For hot pressing temperature of $70^{\circ} \mathrm{C}$, the bond fail time increased to 120-180 s, and the color of the bonded leaves became light green. For hot pressing temperature of $80^{\circ} \mathrm{C}$, the bond fail time increased to $150-180 \mathrm{~s}$. However, the color of the bonded leaves became grey. Therefore, at application rate of $150 \mathrm{~g} / \mathrm{m}^{2}$, the optimal hot pressing temperature was $70-80^{\circ} \mathrm{C}$, and the hot pressing time was 90-120 s.

The surface of tree leaves contains some functional groups, such as hydroxyl group, methylene group, and carboxyl group [18]. These groups could react with function groups, such as hydroxyl groups in the adhesive to form chemical bonds of high strength [19]. In this study, the longer press time and higher press temperature could provide better condition for the formation of strong chemical bonds [20]. Therefore, the bonded tree leaves had better performance in the hot water test. Considering the production efficiency, cost, decorative effect, and bond performance, the optimal pressing parameters were: adhesive application rate: 100 $\mathrm{g} / \mathrm{m}^{2}$; hot press temperature $70^{\circ} \mathrm{C}$; hot press time $120 \mathrm{~s}$.

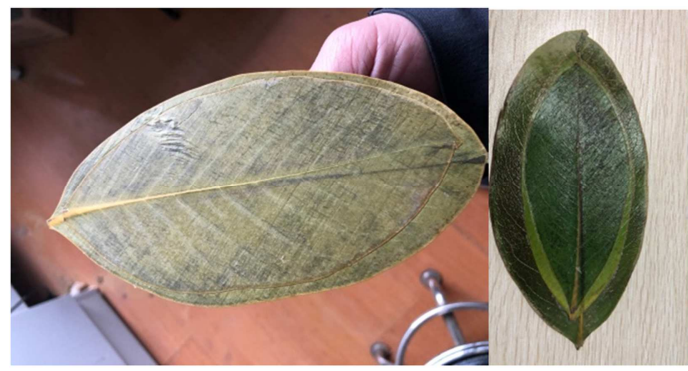

Figure 7. Bonded tree leaves after hot pressing.

Table 3. Bond performance of the adhesive.

\begin{tabular}{|c|c|c|c|c|}
\hline $\begin{array}{l}\text { Adhesive application rate } \\
\left(\mathrm{g} / \mathrm{m}^{2}\right)\end{array}$ & $\begin{array}{l}\text { Hot pressing temperature } \\
\left({ }^{\circ} \mathrm{C}\right)\end{array}$ & Hot pressing time (s) & Bond fail time (min) & Color of the bonded leaves \\
\hline 100 & 60 & 60 & 30 & Green \\
\hline 100 & 60 & 90 & 40 & Green \\
\hline 100 & 60 & 120 & 60 & Green \\
\hline 100 & 70 & 60 & 100 & Light green \\
\hline 100 & 70 & 90 & 130 & Light green \\
\hline 100 & 70 & 120 & $>180$ & Light green \\
\hline 100 & 80 & 60 & 120 & Grey \\
\hline 100 & 80 & 90 & $>180$ & Grey \\
\hline 100 & 80 & 120 & $>180$ & Grey \\
\hline 150 & 60 & 60 & 50 & Green \\
\hline 150 & 60 & 90 & 60 & Green \\
\hline 150 & 60 & 120 & 80 & Green \\
\hline 150 & 70 & 60 & 120 & Light green \\
\hline 150 & 70 & 90 & 140 & Light green \\
\hline 150 & 70 & 120 & $>180$ & Light green \\
\hline 150 & 80 & 60 & 150 & Grey \\
\hline 150 & 80 & 90 & $>180$ & Grey \\
\hline 150 & 80 & 120 & $>180$ & Grey \\
\hline
\end{tabular}

\section{Conclusions}

In this study, the tree leaves (Magnolia Grandiflora) were treated by absolute ethanol for 30, 60, 90, and 120 minutes, respectively. After treatment, the leaves were applied with glycerol to obtain a good waterproof property. Then the treated leaves were bonded by a bio-based adhesive 
synthesized in our lab. The structure, curing characteristics, and physical/mechanical properties of the adhesive were measured and analyzed. The results showed that some reaction happened between function groups in adhesive and function groups on the surface of leaves. To find optimal hot press method, the effects of adhesive application rate, press time, and press temperature on the bonding performance of tree leaves were also investigated. The results showed that the general properties of the bio-based adhesive could meet the requirements for the production of tree leave tableware. After immerged in the water of $63^{\circ} \mathrm{C}$ for 3 hours, some of the bonded leaves could still have good bonds. Considering the production efficiency, cost, decorative effect, and bond performance, the optimal hot pressing parameters were: adhesive application rate: $100 \mathrm{~g} / \mathrm{m}^{2}$; hot press temperature $70^{\circ} \mathrm{C}$; hot press time $120 \mathrm{~s}$. After bonded by bio-based adhesive, the tree leaves could be used as suitable raw materials for the production of green tableware.

\section{Author Contributions}

The Manuscript was written through contributions of all authors. All authors have given approval to the final version of the manuscript. Yifu Yuan and Yan Sun contributed equally and should be considered as co-first authors.

\section{Conflicts of Interest}

The authors declare no competing financial interest.

\section{Acknowledgements}

The authors are grateful for the supports of the Agricultural Science and Technology Fund Project of Shandong Province (Forestry Science and Technology Innovation) (Project No. 2019LY008), Shandong Province Student Innovation and Entrepreneurship Training Program (Project No. S201910434006), and Shandong Agricultural University Student Innovation and Entrepreneurship Training Program "Study on Manufacturing Technology of Green Disposable Tableware”.

\section{References}

[1] C. Li, J. Xu, D. Chen, and Y. Xiao, Detection of phthalates migration from disposable tablewares to drinking water using hexafluoroisopropanol-induced catanionic surfactant coacervate extraction. Journal of Pharmaceutical Analysis, 6 (5), 292-299, 2016.

[2] M. Fieschi, and U. Pretato, Role of compostable tableware in food service and waste management: a life cycle assessment study. Waste Management, 73, 14-25, 2017.

[3] Z. F. Du, Y. P. Xian, F. J. Liu, J. F. Huang, Y. L. Wu, X. D. Guo, Y. H. Wang, and D. H. Luo, Determination of five fluorescent whitening agents in foam plastic tableware by high performance liquid chromatography tandem mass spectrometry. Modern Food Science and Technology, 29 (12), 3014-3018, 2013.
[4] K. Hamad, M. Kaseem, and F. Deri, Recycling of waste from polymer materials: An overview of the recent works. Polymer Degradation and Stability, 98 (12), 2801-2812, 2013.

[5] G. Behrendt, and B. W. Naber, The recycling of polyurethanes (review). Journal of the University of Chemical Technology and Metallurgy, 44 (1), 3-23, 2009.

[6] N. Rastkari, M. Z. Jeddi, M. Yunesian, and R. Ahmadkhaniha, Effect of sunlight exposure on phthalates migration from plastic containers to packaged juices. Journal of Environmental Health Science and Engineering, 16 (1), 27-33, 2018.

[7] Y. Sun, and S. Lin, A feasibility study on the transformation and sustainable development of "disposable tableware" in Taiwan night market. In: Rau PL. (eds) Cross-Cultural Design. Culture and Society. HCII 2019. Lecture Notes in Computer Science, vol 11577. Springer, Cham, 2019.

[8] P. Saravanan, S. Sathish, D. Visvanathan, S. Silambarasan, and A. Charles, Safe food packing and storage for better health and environment. International Journal of Integrative Sciences, Innovation and Technology, 1 (5), 1-4, 2012.

[9] M. Rowe, E. Eyiler, and K. B. Walters, Bio-based plasticizer and thermoset polyesters: a green polymer chemistry approach. Journal of Applied Polymer Science, 133 (45), 43917-43920, 2016.

[10] D. Zheng, Y. Q. Wang, Y. M. Deng, A. B. Yu, and W. H. Li, Research on Mechanical Properties and Simulation of Straw-Biodegradable Tableware, Applied Mechanics and Materials, 101-102, 1096-1100, 2012.

[11] Y. F. Pang, W. T. Xu, Q. Li, C. Li, and A. Mao, Research progress of bio-based wood adhesives. China Forest Products Industry, 45 (4), 3-7, 2018.

[12] X. Kong, G. Liu, and J. M. Curtis, Characterization of canola oil based polyurethane wood adhesives. International Journal of Adhesion and Adhesives, 31, 559-564, 2011.

[13] Q. Li, M. Li, C. Chen, G. Cao, A. Mao, and H. Wan, Adhesives from polymeric methylene diphenyl diisocyanate resin and recycled polyols for plywood. Forest Products Journal, 67 (3/4), 275-282, 2017.

[14] J. Haydary, S. Dalibor, Characterization of automobile shredder residue for purpose of its thermal conversion. Journal of Solid Waste Technology and Management 41 (1): 41-49, 2015.

[15] O. J. Kwon, S. R. Yang, D. H. Kim, and J. S. Park, Characterization of polyurethane foam prepared by using starch as polyol. Journal of Applied Polymer Science, 103 (3), 1544-1553, 2007.

[16] Z. H. Gao, W. B. Wang, X. Y. Zhao, and M. R Guo, Novel whey protein-based aqueous polymer-isocyanate adhesive for glulam. Journal of Applied Polymer Science, 120 (1), 220-225, 2010 .

[17] S. H. Lee, T. Ohkita, and Y. Teramoto, Polyol recovery from biomass-based polyurethane foam by glycolysis. Journal of Applied Polymer Science, 95 (4), 975-980, 2005.

[18] A. Mao, W. Xu, E. Xi, Q. Li, and H. Wan, Evaluation of phenol-formaldehyde resins modified and blended with pyrolysis bio-oil for plywood. Forest Products Journal, 68 (2), 113-119, 2018. 
[19] Y. Shin, E. M. Winder, K. S. Han, H. Lee, and G. T. Bonheyo, Enhanced capacities of mixed fatty acid-modified sawdust aggregators for remediation of crude oil spill. ACS Omega, 4 (1), 412-420, 2019.
[20] P. Wei, X. Rao, J. Yang, Y. Guo, H. Chen, Y. Zhang, S. Chen, $\mathrm{X}$. Deng, and $\mathrm{X}$. Wang, Hot pressing of wood-based composites: a review. Forest Products Journal, 66 (7/8): 419-427, 2016. 